\title{
Natural Source Constitutes Effective Route for Processing of Silver Nanoparticles for Medical Textile
}

\author{
R.Refaei ${ }^{1}$, S.Shaarawy ${ }^{1 *}$, M.K. Elbisi ${ }^{1}$, F.H.Motawe ${ }^{2}$ and A.El-Shafei ${ }^{1}$ \\ ${ }^{1}$ National Research Centre (Scopus affiliation ID 60014618), Pre-treatment and \\ Finishing of Cellulosic Fibers Department, Textile Research Division, 33El-Behouth \\ St. (former El-Tahrir str.), Dokki, P.O. 12622, Giza, Egypt. \\ ${ }^{2}$ National Research Centre (Scopus affiliation ID 60014618), Microbial Chemistry \\ Department Genetic Engineering and Biotechnology Research Division, 33El- \\ Behouth St. (former El-Tahrir str.), Dokki, P.O. 12622, Giza, Egypt.
}

\begin{abstract}
D UE TO great calling for medical and antimicrobial textiles based on eco-friendly natural agents, silver nanoparticles were prepared using herbal extract peppermint, tulsi, chamomile, sage and green tea at optimized conditions. Plant extracts are very cost effective, eco-friendly and thus can be economic alternatively for large-scale synthesis of nanoparticles. In this research firstly, the herbal extracts were prepared by aqueous method, secondly using of herbal extracts in synthesis of silver nanoparticles from aqueous solutions of silver nitrate $\left(\mathrm{AgNO}_{3}\right)$. Synthesis of silver nanoparticles was characterized and confirmed by UV-visible spectroscopy and TEM. The herbal extracts and silver nanoparticles were applied in presence of eco-friendly finishing agent (glyoxal, aluminuim sulphate) on cotton fabrics which in turn characterized using scanning electron microscopy (SEM), (EDX) patterns, physical properties as tensile strength, water permeability, air permeability and roughness were also analyzed. Final characterization of treated cotton fabric against antimicrobial activity including gram negative strain, gram positive strains in addition to yeasts unicellular fungi. The results showed that cotton treated with AgNPs synthesis from herbal extracts had better antimicrobial activity.
\end{abstract}

Keywords: Plant extracts, Antimicrobial agents, Silver-nanoparticles, Cellulose fibers, Medical textile.

\section{Introduction}

Antimicrobial finishing for textiles dates back to the ancient Egyptians, who applied herbs and spices to preserve mummy wrapping [1]. Today many different synthetics and natural compounds such as triclosan, quaternary ammonium, polybiguanides, N-halamines, silver and chitosan have been developed to impart antimicrobial properties to textiles [2-5]. Lately investigation into natural antimicrobial agents, such as extracts from tiny plants types as neem, aloe vera, capsaicin, etc., have received great importance due to their green nature [6]. It has been found that natural antimicrobial agents display largespectrum activity against bacteria and fungi, but they still have some notes in terms of efficacy and durability[7].

Several studies with reference to natural products have elucidated significant progress in the discovery of new component with antimicrobial activity from natural products. Plants as a major source of natural antimicrobials in nature have received a lot of research studies lately [8]. The extraction which produced from different parts of plants containing materials as flavonoids tannin, and quinonoids with strong antimicrobial properties, have been studied [9]. Several studies have shown that natural materials such as phenolic, terpenoids and alkaloids compounds possess strong antimicrobial activity[10]. Many of these natural antimicrobial agents are usually in plant cells, but their composition is variable and have highest antimicrobial activity so used for therapeutic purposes [11]. Natural antimicrobial agents can be applied to textile by different methods such as pad-dry-cure, coating, spray and foam techniques.

*Corresponding author e-mail: sahar.shaarawy@yahoo.com

DOI: 10.21608/ejchem.2018.4148.1365

(C)2017 National Information and Documentation Centre (NIDOC) 
Green Chemistry synthesis methods are now popular in chemical technologies. The main goal is including the need for greener ways against the higher costs and higher energy requirements of physical and chemical processes. The reason is that conventional methods for nanoparticle synthesis usually require harmful reductants such as sodium borohydride or hydrazine and many steps in the synthesis procedure including heat treatments, often producing hazardous byproducts. In order to reduce the environmental impact of nanoparticle synthesis, greener routes have been investigated.

It was evident that the production of metal nanoparticles using plant extracts could be done in the metal salt solution during minutes, depending on the nature of the plant extract. After the selection of the plant extract, the main parameters affecting the preparation of nanoparticles are the concentration of the extract, the temperature, the $\mathrm{pH}$, and the contact time $[12,13]$.

Nano particles have a wide range of applications such as electronics, catalysis, energy and medicine have gained commercial acceptance [14]. Besides improving their functionality, the use of nano technology can result in the production of textiles with completely novel properties or the combination of various functions [15]. Such multifunctional textiles include antistatic textiles, reinforced textiles, antibacterial, self cleaning textiles, bleaching resistant, etc. and paves the way for the use of its products in other fields outside the traditional industries [16-18]. Preparation of silver nanoparticles via using biomolecules extracted from plants is favored and offer superiority than chemical methods.

Increasing demands towards green chemistry, green way for preparing of metal nanoparticles lead an interest to promote less hazard techniques. advantages of synthesis of silver nanoparticles using plant extracts are that it is economically, cost saving; and decrease pollution so leading to almost clean products.

The present investigation aims to develop antimicrobial finish for cotton fabrics from herbal extracts of peppermint, tulsi, chamomile, sage and green tea which firstly prepared via aqueous method [6]. Some selective species of plants were identified and screened for their antimicrobial activities. Their extracts were then used for silver nanoparticles preparation and the nanoparticles were characterized by using UV visible and TEM. The aforementioned prepared silver nanoparticles were applied to cotton fabric. A comprehensive study was proceeded to assess the antimicrobial activity against gram negative strain, gram positive strains in addition to yeasts unicellular fungi of the treated fabrics. The fabrics were subjected to wash durability testing to find the durability. Characterization was done for the treated cotton using scanning electron microscopy (SEM), (EDX) patterns and physical properties as tensile strength, water and air-permeability and roughness were also analyzed.

\section{Experimental}

\section{Material}

The desized, scoured and bleached cotton fabric will be purchased from Mehalla-Alkoubra. The fabric was purified by scouring at $100^{\circ} \mathrm{C}$ for 60 min. using a solution containing $\mathrm{Na}_{2} \mathrm{CO}_{3}(2 \mathrm{~g} / \mathrm{l}$, wetting agent, $1 \%$ ), then thoroughly washed with water and dried at ambient conditions. Glyoxal, Aluminum Sulphate was of laboratory scale.

\section{Methods}

\section{Herbal plants collection}

The present works prepared and evaluated the natural antimicrobial textile finishes extracted from peppermint, tulsi, chamomile, sage and green tea. The dried plants were purchased from local department. The dried plants were converted into fine powder by using dry grinding machine

\section{Preparation of Herbal extracts solution}

$10 \mathrm{gm}$ of dried herbal Powder was shacked in $100 \mathrm{ml}$ of hot water at $100^{\circ} \mathrm{C}$ for one hour, after that the extract solution left to cool and then filtered. The filtrate extract was collected and stored at $4^{\circ} \mathrm{C}$ in dark bottles which further used for preparation of nanoparticles.

\section{Preparation of silver nanoparticles using Herbal Extract}

The preparation of silver nano particles was done using $10 \mathrm{ml}$ from five herbal extracts were taken and the $\mathrm{pH}$ was adjust using sodium hydroxide $0.1 \mathrm{~N}$ to $\mathrm{pH} 9$, then distilled water was added till $100 \mathrm{ml}$. the temperature was raised to $70^{\circ} \mathrm{C}, 1 \mathrm{ml}$ silver nitrate $(0.1 \mathrm{~N})$ was added under stirring, the solution was kept at this temperature under stirring for additionally $30 \mathrm{~min}$ until color change to yellowish brown as seen in Scheme1 the analysis for silver nanoparticles prepared was confirmed with UV-visible spectroscopy [19]. 


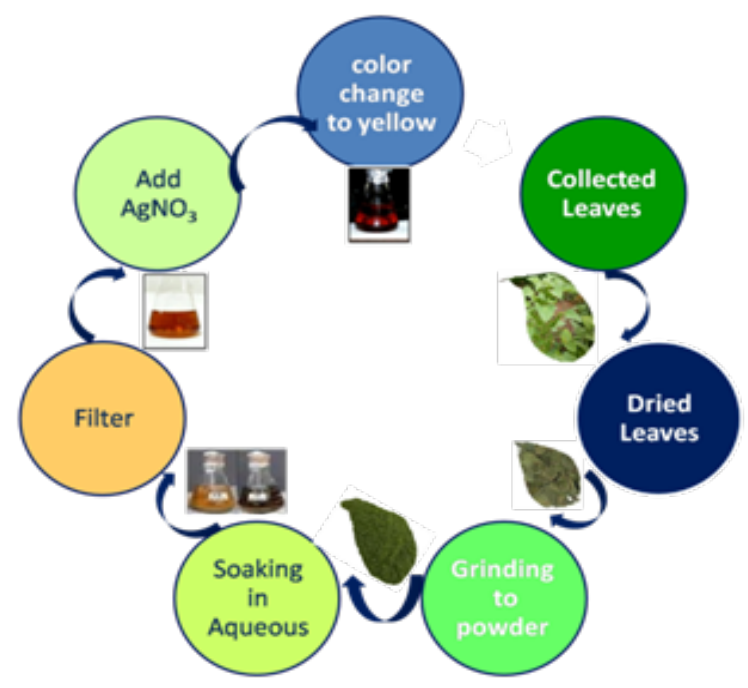

Scheme 1. Protocol for synthesis of silver nanoparticles using plant extract.

Cotton Fabric treatment with silver nanoparticles prepared with herbal extracts

The synthesized and characterized nanoparticles previously prepared from herbal extracts solutions were applied on the cotton fabrics using pad dry cure method. This treatment was done in presence of glyoxal as an eco- friendly crosslinking agent. The cotton fabrics were treated with the five previous herbal extracts finishing formula as follow: $2 \%$ of silver nanoparticles prepared from five herbal extracts which mixed with $6 \%$ of glyoxal as crosslinking agent and $4 \%$ aluminum sulphate $\mathrm{Al}_{2}\left(\mathrm{SO}_{4}\right)_{3}$ was added as a catalyst. Cotton fabrics were padded dip and nip in the finishing formula to a $100 \%$ wet pick-up was maintained for all of the treatments. After padding, the fabrics were dried and then cured at $120^{\circ} \mathrm{C}$ for $3 \mathrm{~min}$. Subsequently, it was immersed in a solution of $2 \mathrm{~g} / \mathrm{l}$ of sodium lauryl sulfate for $5 \mathrm{~min}$ to remove the unbound extract, and then rinsed to remove the soap solution and finally air-dried; then the dried treated fabrics were under characterizations.

Characterization of silver nanoparticles and treated fabric

- Tensile strength was determined by the strip method according to ASTM, Standard Test Method accordance with ASTM D5035

- Water permeability AATCC method 39-1980

- Air permeability ASTM D737-96

- Roughness was measured according to AATCC standard test method using a Surfacoder (1700a).
- The surface morphology of treated fabrics was established by using scanning electron microscope (SEM), EDX

- Transmission Electron Microscopy TEM: Shape and size of AgNPs were practically obtained using TEM; JEOL-JEM-1200.

- Ultraviolet-visible(UV-vis) spectrophotometer have been proved to be quite sensitive to the formation of AgNPs because AgNPs exhibit an intense absorption peak around $400 \mathrm{~nm}$ due to the surface plasmon excitation which describes the collective excitation of conductive electrons in a metal. The absorption spectrum of each herbal solution after the removal of fabrics sample was recorded in the range 600-250 nm using (UV1800 Shimadzu, Germany).

Antibacterial tests

All antibacterial activity tests were done in triplicate to ensure reproducibility. The antibacterial activity of fabric samples was evaluated using, (ATCC 1533) bacteria using disk diffusion method. A mixture of nutrient broth and nutrient agar in $1 \mathrm{~L}$ distilled water at $\mathrm{pH} 7.2$ as well as the empty Petri plates were autoclaved. The agar medium was then cast into the Petri plates and cooled in laminar airflow. Approximately 105 colony-forming units of bacteria were inoculated on plates, and then $292 \mathrm{~cm}^{2}$ of each fabric samples was planted onto the agar plates. All the plates were incubated at $37^{\circ} \mathrm{C}$ for $24 \mathrm{~h}$ and examined if a zone of inhibition was produced around samples. 


\section{Antimicrobial assay}

The antimicrobial activities of the silver nanoparticles prepared from herbal extracts were determined using agar plate as follow. The plates were incubated at $37^{\circ} \mathrm{C}$ or $24 \mathrm{~h}$ a growth free zone of inhibition around the fabric appears as antibacterial agent migrates from the fabric onto the agar and diffuses outward. Diameter of inhibition zone was determined according to AATCC test method 100-199

\section{Antimicrobial activities assessment}

Antibacterial activities and antifungal of silver herbal extract were tested in vitro against different microorganisms including gram negative bacteria (salmonella tyhimurium, Escherichia Coli) and the gram positive, bacillus cereus, staphylococcus aureus and yeasts unicellular fungi (candida albicans, Candida tropical's 750 )

\section{Results and Discussion}

\section{$U V$-Vis spectroscopic}

Scheme 1 shown the formation of yellowish brown color in the reaction solution indicates the formation of silver nanoparticles. The reduction of silver ions in the colloidal solution was confirmed by UV-Visible spectroscopy. The change in color of the solution was due to the surface plasmon resonance (SPR) and reduction of silver ions by aqueous extract of peppermint, tulsi, chamomile, sage and green tea. Moreover, the UV-Vis absorption spectrum of AgNPs in the range of 200-800 $\mathrm{nm}$ at the optimum condition revealed a peak at $418 \mathrm{~nm}$ (Fig. 1). This strong SPR peak proves the formation of silver nanoparticles. The color of the solution begun to change by the addition of aqueous plant extract and by time of incubation there was no significant change, neither in color nor in the SPR peak. Moreover, $\mathrm{AgNO}_{3}$ solution which was used as control showed no color change. influence of addition of herbal extract during synthesis of silver nanoparticles faint yellow, yellowish brown colors slowly appeared in the mixture, indicating the formation of Ag-NPs and finally turn into yellowish brown color (Scheme 1). The characterization absorption spectra was the important properties of the AgNPs, and the UV-Vis spectra was a good method for characterization of the formation and growth of Ag NPs.

Transmission Electron Microscopy TEM, Scanning Electron Microscope SEM, EDX

The characterization of the AgNPs was observed by TEM as shown in Fig. 2-6. The TEM images of AgNPs exhibit that spherical like morphology nanoparticles and their sizes from 20 to $10 \mathrm{~nm}$. The very slight agglomeration was occurred, which may be due to possible deposition at the latter stage of the reaction. The relatively high levels of the steroids, sapogenins, carbohydrates and flavonoids act as reducing agents and phytocomponent as the capping agents which prolong stability to silver nanoparticles. By increasing concentration of extract during the period of incubation, silver nanoparticles showed gradual change in color of the extracts to yellowish brown with peppermint and tulsi extract as shown

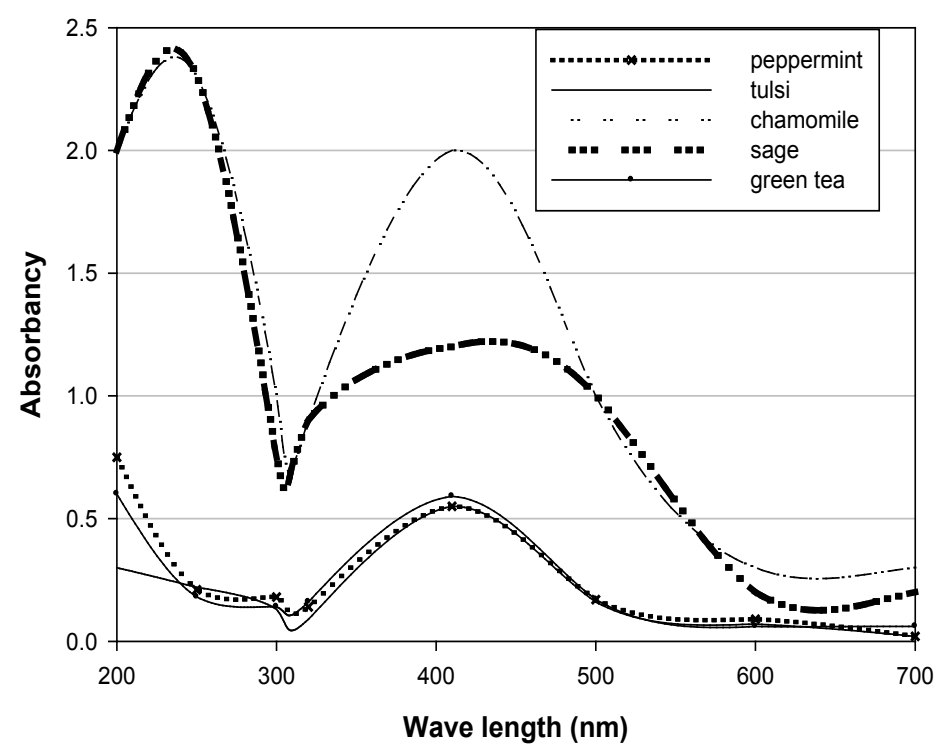

Fig. 1. UV-Visible of preparation of silver nanoparticles using different herbal extracts. 
in Scheme 1. Transmission electron microscopy (TEM) analysis indicate that these nanoparticles were spherical and uniformly distributed due to the presence of different stabilizing function groups as carbonyl, hydroxyl, etc. in different herbal extracts $[20,21]$. This data confirmed the antimicrobial results obtained and TEM which ensure the formation of AgNPs in spherical shape separated no-aggregation occur.

The composition of AgNPs - cotton fabric is confirmed by SEM, EDX as shown in Fig. 2-6 for 5 herbal under investigation i.e. (peppermint, tulsi, chamomile, sage and green tea). EDX for all herbal extracts treated cotton fabric has a higher $\%$ of $\mathrm{C}, \mathrm{O}$ which indicate the presence of cotton fabric while $\mathrm{Ag}^{\circ} \%$ present in range from( $0.16-4.05)$ where the lowest $\%$ detected for

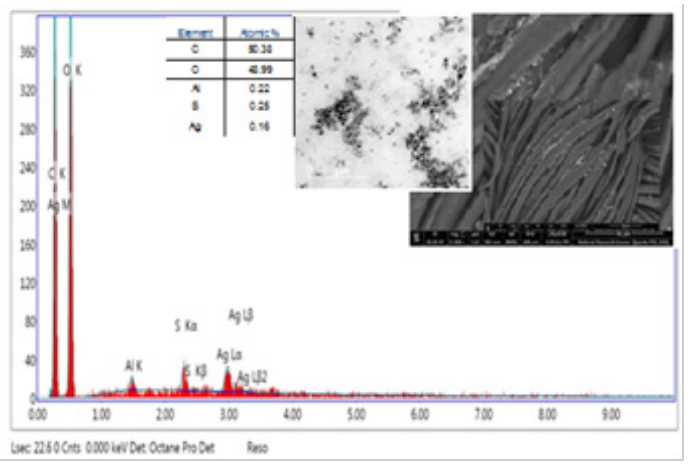

Fig. 2. SEM, Edex, TEM of Peppermint extracts.

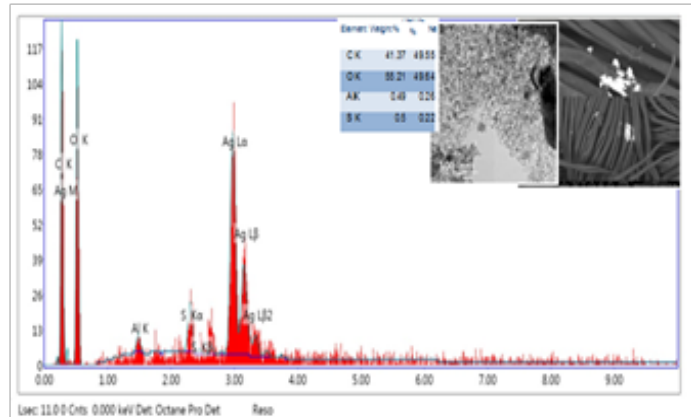

Fig. 4. SEM, Edex, TEM of chamomile extracts. peppermint, chamomile $<2$, medium $\%$ for tulsi, green tea $=2$, finally the best and most effective herbal in reduction of $\mathrm{Ag}$ ions on cotton fiber is sage as it realizes higher deposition on cotton fabric treated $\%=4.05$

Scanning electron microscopy investigation (SEM) determine the morphology and size of the synthesized Ag-NPs. The silver nanoparticles formed with the 5 herbal by reduction method were predominantly round with diameters 18 $\mathrm{nm}$. This image further indicates that the silver nanoparticles are not aggregated which mean that mono disperses in nature due to repulsion forces. It's clear that a repulsive force due to different charges prohibit aggregation (Fig. 2-6). sage was the most effective extract with high effective components act as capping and reducing agent.

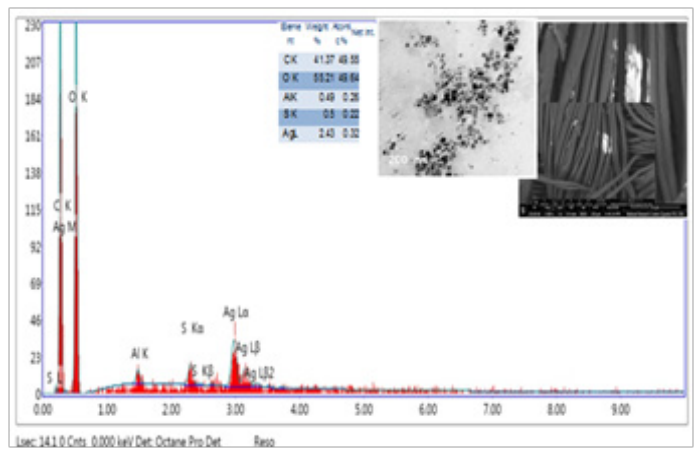

Fig. 3. SEM, Edex, TEM of Tulsi extracts.

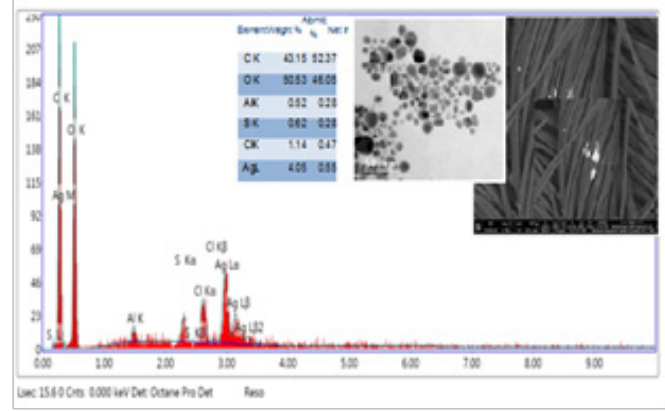

Fig. 5. SEM, Edex, TEM of Sage extracts.

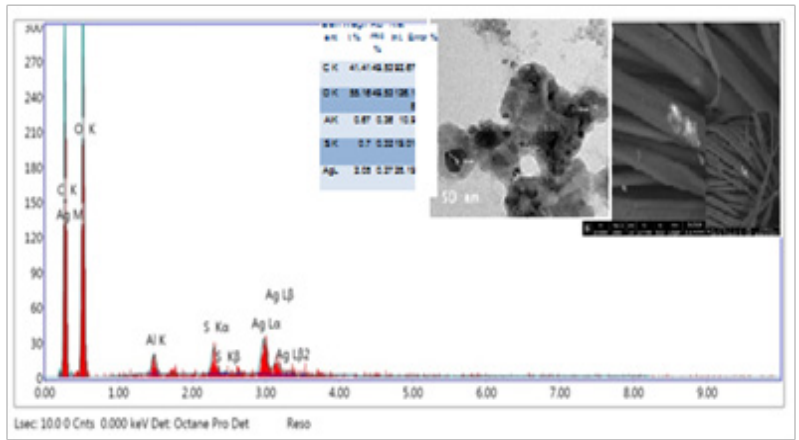

Fig. 6. SEM, Edex, TEM of Green Tea. 


\section{Evaluation of physical properties of finished} cotton fabric

Table 1 shows the physical properties of cotton treated with peppermint, tulsi, chamomile, sage and green tea herbal extracts and silver nanoparticles in presence of eco friendly crosslinking agent -glyoxal/aluminum sulphate as catalyst- from the table it is observed that:

- Tensile strength was shown that the presence of crosslinking agent makes deterioration in the fabric strength which in turn improved by the presence of five herbal extracts. This was mainly due to the organic molecules of the extracts adsorbed in the voids of the fabric which helps resistance of the tensile load on stress and also for the elongation. As the nano particles coated the fibers and penetrate them this makes fabric more durable and long lasting via increasing tensile strength. the improvement of the tensile strength ordered as Peppermint $>$ Tulsi, Sage $>$ Chamomile, Green tea depends on the percent of organic molecules.

- Air permeability is an effective parameter evaluate the comfort and performance of textile. The air permeability of the herbal extracts treated fabrics was found be almost equal to that of the untreated fabrics which improved that the herbal extracts save and protect the good properties of cotton. The air permeability of the nanoparticles treated fabrics was between $(31-27 \mathrm{~cm} 3 / \mathrm{cm} 2 / \mathrm{sec})$ while that of the untreated fabric was $33.52 \mathrm{~cm} 3 / \mathrm{cm} 2 /$ sec. Obviously, it could be interpreted that the breathability of the treated fabrics was not altered significantly by the presence of nanoparticles on it. The uniform and very thin distribution of the nanoparticles on the fabric surface could be attributed to the fact that there is no deformation of porous over treatment noticed. [22] have opined that the changes in air permeability of the fabric samples will not be significant if the size of the coated particles is smaller than the size of the fabric holes.

- Water vapour permeability is the ability of penetrating vapour through the fabric. The ability of fabric to transport water vapour is a determination of comfort $[23,24]$. Natural fibers such as cotton, bamboo and wool are characterized by high absorption levels [25]. In order to explore the filtration performance of cotton fabric after treatment with five herbal extracts the mass of water through the cotton fabric within a specified time is measured. Water permeability of fabric doesn't change marginally before and after treatment. water permeability rate assumes the linear positive correlation in all herbal under investigation except green tea.

- Roughness explained as an integral of surface criteria. It is determined by the variation in the direction of a surface from its fitting form. If there is notable difference, the surface is rough; and vice versa. However, controlled roughness can be predominating be desirable. Roughness has an efficient role in determining how an object will interact with its environment. Roughness is often a perfect predictor of the performance of a mechanical component, since irregularities on the surface may form sites for cracks. Although a high roughness value is predominating unfavorable, it can be too arduous and costly to control in manufacturing. Decreasing the roughness of a surface usually increases its manufacturing cost. The roughness was improved by chamomile extract which makes an improvement in the surface roughness change from $(13,97-11.87)$ this may be related to increasing the surface negativity for the cotton fabric after treatment which results in an increase adhesion to the fabric. chamomile imparts textiles soft feeling while peppermint, green tea, tulsi has no significant effect $(13.18,13.51,14.95)$ except sage causes decrement of roughness become 11.8

Antibacterial properties of treated cotton fabric

Recently discovering antimicrobial agents from various sources to combat microbial resistance become urgently. Figure 7(a-e) respectively show the antimicrobial properties of cotton fabric treated with silver nanoparticles

TABLE 1 Physical properties of the fabric treated with silver nano particles and herbal extracts.

\begin{tabular}{|c|c|c|c|c|c|}
\hline Herbal used & $\begin{array}{c}\text { Tensile } \\
\text { strength Kg. }\end{array}$ & Elongation \% & $\begin{array}{c}\text { Air permeability } \\
\mathbf{c m}^{\mathbf{3} / \mathbf{c m}^{3} / \mathbf{s e c} .}\end{array}$ & $\begin{array}{c}\text { Water } \\
\text { permeability } \\
\text { L.cm } \mathbf{s} \mathbf{s e c}\end{array}$ & Roughness $^{\mathbf{0}}$ \\
\hline Peppermint & 40 & 12 & 31.65 & 1.5 & 13.18 \\
\hline Tulsi & 30 & 12 & 32 & 1.562 & 14.95 \\
\hline Sage & 30 & 12 & 27 & 1.562 & 18.7 \\
\hline Chamomile & 20 & 12 & 32 & 1.538 & 11.87 \\
\hline Green tea & 20 & 12 & 33.5 & 1.492 & 13.51 \\
\hline Cotton with crosslinker & 21 & 13 & 30.77 & 0.313 & 16.6 \\
\hline Blank & 50 & 21 & 33.52 & 1.5 & 13.97 \\
\hline
\end{tabular}

Egypt. J. Chem. 61, No. 6 (2018) 
previously prepared with five herbal extracts peppermint, tulsi, chamomile, sage and green tea. Figures show the antimicrobial activity against Escherichia coli, Salmonella tyhimuium (gram negative bacteria- ve), Staphylococcus aureus, Bacillus (gram positive bacteria $+v e$ ) and candida Tropica (Fungi or yeast), respectively.

Several methods evaluate the antimicrobial property of this natural sources (extract). The diskdiffusion methods are the most known and basic methods. antimicrobial activity of treated cotton with Ag-NPs /extracts evaluated depending on the mean diameter of inhibition zone according to Inhibition zone is one of the most interesting, effective methods to combat microbial resistance [26]. Currently, the determination of antimicrobial activity before and after 5,10,15 till 30 washing cycles was considerable. Plant extracts provide a huge range of structures and compounds so phytochemical study focuses on the comparison between the results. Most of the extracts show good antimicrobial activity against salmonella tyhimuium, Bacillus cereus before washing and moderate activity after washing but all of them were more active before washing.

The investigation of cotton fabric treated with 5 herbal extracts and Ag-NPs (Fig. 7a-e) essential shows that the strong adhesive ability of Ag-NPs nanoparticles results in excellent durable coating on cotton fabrics, and thus the excellent antibacterial properties have been preserved after washing. Silver ions are formed with moisture which becomes more active than silver ionized form [27]. Thus, all forms of silver or silver containing compounds with observed antimicrobial properties are in one way of silver ions $(\mathrm{Ag}+)$; these silver ions incorporated and released by time [28]. This is may be attributed to the electrostatic attraction [29]. These nanoparticles causing damage to cell wall of the bacteria.
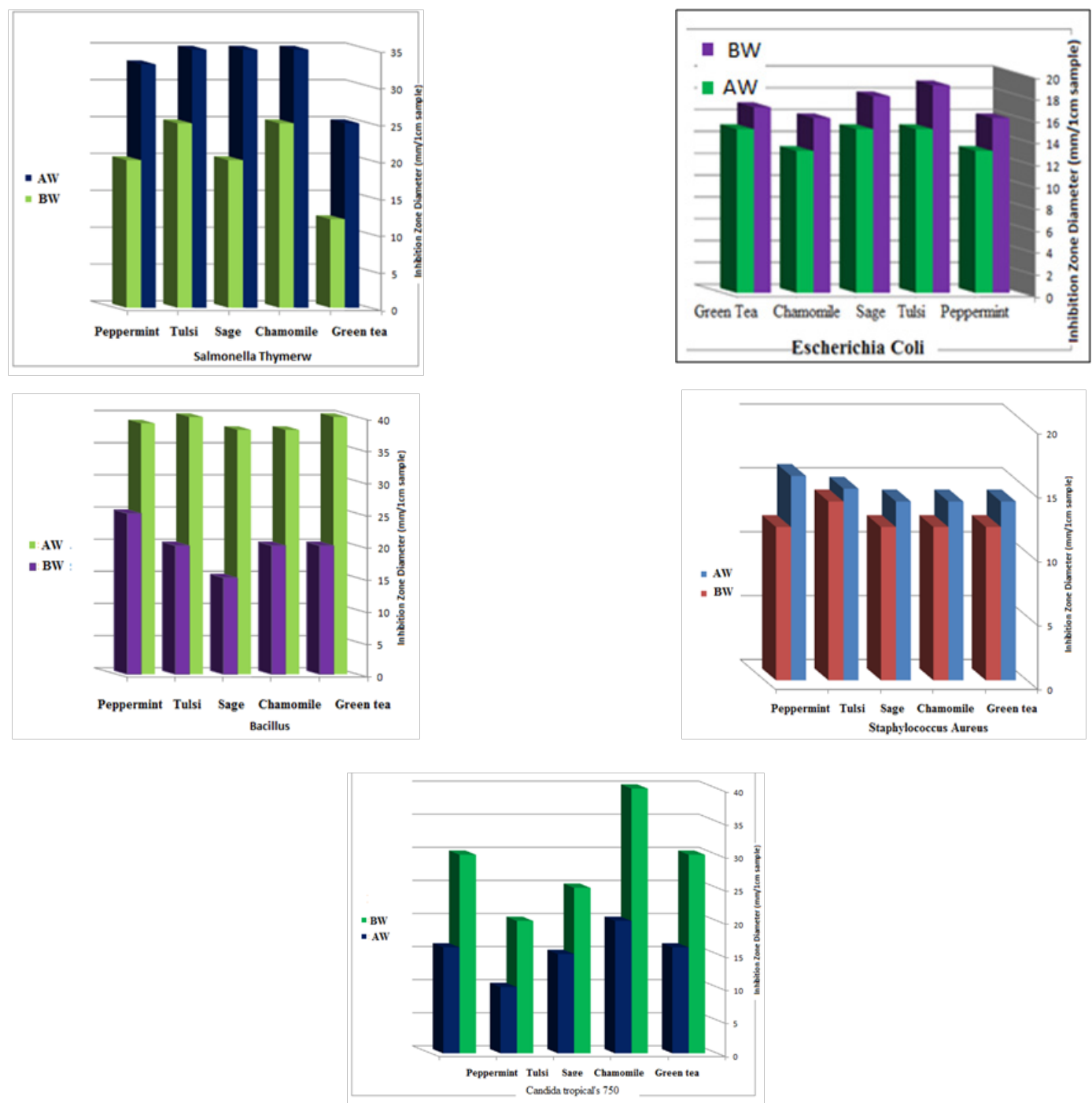

Fig. 7. A-E Antimicrobial activity of five herbal extracts against inhibition zone diameter.

Egypt. J. Chem. 61, No. 6 (2018) 
From the experimental results, it can be concluded that plant extract used in preparing silver nanoparticle and after that treated cotton could be used as an antimicrobial cotton for medical use. The preparation procedure used in this study, two-step process, offers easy formation, varieties and sustainability of the prepared formulations. Results from UV-visible spectroscopy TEM and SEM characterization of the prepared silver nano particles are suitable in size and no aggumlation occurs, also the treated cotton fabric has excellent resistance against +ve , -ve and fungi which scope with the target of this research, the produced treated fabrics were evaluated as antibacterial fabric and characterized by Scanning Electron Microscopy (SEM) and it is recommended to be used in the field of medical textile.

\section{Acknowledgment}

The authors would like to acknowledge and express their gratitude to In-house Project Office at National Research Centre of Egypt to fund this research and facilitate all the capabilities to finish this work under project ID \#11090323

\section{References}

1. Shahidi S. and Jakub W., Antibacterial agents in textile industry. International Journal of Textile Science, 4(3), 387- 406 (2013).

2. Gao Y. and Cranston R., Recent advances in antimicrobial treatments of textiles. Textile Research Journal; 78(1), 60-72 (2008).

3. Purwar R. and Joshi M., Recent developments in antimicrobial finishing of textiles - A review. AATCC Review, 4, 22-26 (2004).

4. Simoncic B. and Tomsic B., Structures of novel antimicrobial agents for textiles - A review. Textile Research Journal, 80(16), 1721-1737 (2010).

5. Li R., Hu P., Ren X., Worley S.D. and Huang T.S., Antimicrobial N-halamine modified chitosan films. Carbohydrate Polymers, 92(1), 534-539 (2013).

6. El-Shafei A., Shaarawy S., Motawe F.H., Refaei R., Herbal extract as an ecofriendly antibacterial finishing of cotton fabric. Egyptian Journal of Chemistry, 61(2), 250-260 (2018).

7. Hussain A.I., Anwar F., Chatha S.A.S., Latif S., Sherazi S.T.H. and Ahmad A., Chemical composition and bioactivity studies of the essential oils from two Thymus species from the Pakistani flora. $L W T$ - Food Science and Technology, 50(1), 185-192 (2013).

8. Kenny O., Smyth T.J., Walsh D., Kelleher C.T.,

Egypt. J. Chem. 61, No. 6 (2018)
Hewage C.M., Brunton N.P., Investigating the potential of under-utilised plants from the Asteraceae family as a source of natural antimicrobial and antioxidant extracts. Food Chemistry, 161(0), 7986 (2014).

9. Hübsch Z., Van Zyl R.L., Cock I.E., Van Vuuren S.F., Interactive antimicrobial and toxicity profiles of conventional antimicrobials with Southern African medicinal plants. South African Journal of Botany, 93(0), 185-197 (2014).

10. Okunola A., Muyideen T.H., Chinedu P. Anokwuru, Tomisin J., Harrison A., Victor U.O., Babatunde EE., Comparative studies on antimicrobial properties of extracts of fresh and dried leaves of Carica papaya (L) on clinical bacterial and fungal isolates. Advances in Applied Science Research, 3(5), 3107-3114 (2012).

11. Gutarowska B., Machnowski W., Kowzowicz Ł., Antimicrobial activity of textiles with selected dyes and finishing agents used in the textile industry. Fibers and Polymers, 14(3), 415-422 (2013).

12- Raveendran P., Fu J. and Wallen S. L., Completely "Green" Synthesis and stabilization of metal nanoparticles, Journal of the American Chemical Society, 125 (46), 13940-13941 (2003).

13- Mittal A. K., Chisti Y. and Banerjee U. C., Synthesis of metallic nanoparticles using plant extracts. Biotechnology Advances, 31, 2, 346-356 (2013).

14- Salata O., Applications of nanoparticles in biology and medicine. J. Nanobiotechnology, 2(1), 3 (2004).

15- Deshpande R., Bedre D.M., Basavaraja S., Balaji S.D., Manjunath S.Y., et al. Microwave-assisted rapid extracellular synthesis of stable biofunctionalized silver nanoparticles from guava (Psidium guajava) leaf extract. J Nanopart Res, 13(5), 2021-2028 (2011).

16- Gupta D., Antimicrobial treatments for textiles. IJFTR, 32(2), 254-263 (2007).

17- Kathirvelu S., Dsouza L., Dhurai B., UV protection finishing of textiles using $\mathrm{ZnO}$ nanoparticles. IJFTR, 34(3), 267-273 (2009).

18-Sivakumar A., Murugan R., Sundaresan K., Periasamy S., UV protection and self-cleaning finish for cotton fabric using metal oxide nanoparticles. IJFTR, 38(3), 285-292 (2013).

19- Hebeish A., El-Bisi M.K., El-Shafei A., Green synthesis of silver nanoparticles and their application to cotton fabrics. International Journal of Biological Macromolecules, 72, 1384-1390 (2015). 
20- Sadeghi B., Gholamhoseinpoor F., A study on the stability and green synthesis of silver nanoparticles using Ziziphora tenuior (Zt) extract at room temperature. Spectrochim Acta Part A:Mol Biomol Spectrosc, 134, 310-5 (2015).

21-Veeraputhiran V., Bio-catalytic synthesis of silver nanoparticles. Int J Chem Tech Res; 5(5), 255-2562 (2013).

22- Dastertjerdi R. M., Montazer S., Shahsavan A., A novel technique producing durable multifunctional textiles using nanocomposite coating. Colloids and Surfaces B:Biointerfaces. 81, 32-41 (2010).

23- Skenderi Z., Čubrić I.S., Srdjak M., Water vapour resistance of knitted fabrics under different environmental conditions. Fibres \& Textiles in Eastern Europe, 17(2), (73), 72-75 (2009).

24. Wang F., Zhou X., Wang S., Development processes and property measurements of moisture absorption and quick dry fabrics. Fibres \& Textiles in Eastern Europe, 17, 2(73), 46-49 (2009).

25. Ermulu N., Ozipek O., Investigation of regenerated bamboo fibre and yarn characteristics. Fibres \&Textiles in Eastern Europe, 16, 4(69), 43-47 (2008).

26. Landerkin,G. B., Smith, J. R. G. \& Lochhead, A. G. A study of the anti- biotic activity of actinomycetes from soils of northern Canada. Canad. J. Res. C, 28, 690 (1950).

27. Cao Y.W., Jin R., Mirkin C.A., DNA-modified core-shell Ag/Au nanoparticles. J. Am Chem Soc, 123, 7961-2 (2001)

28. Sondi I., Sondi B.S., Silver nanoparticles as antimicrobial agent: A case study on E. coli as a model for gram negative bacteria. J. Colloid Interface Sci; 275(1), 177-82 (2004).

29. Matthew Eby D., Schaeublin Nicole M., Farrington Karen E., Hussain Saber M., Johnson G.R., Lysozyme catalyzes the formation of antimicrobial silver nanoparticles. ACS Nano, 3(4), 984-94 (2009).

(Received 13/6/2018; accepted 2/8/2018)

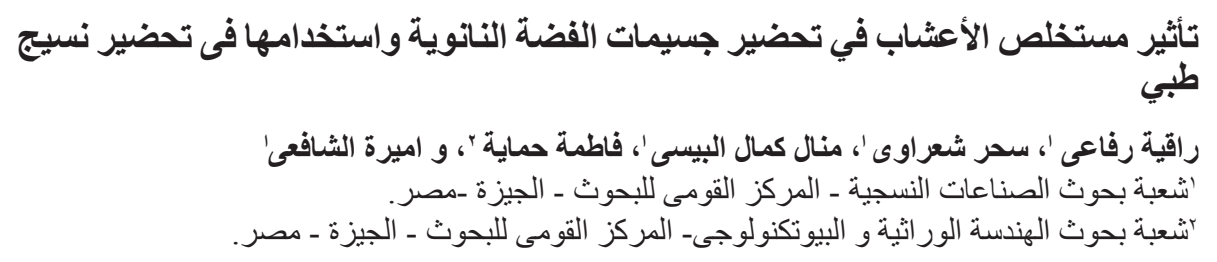

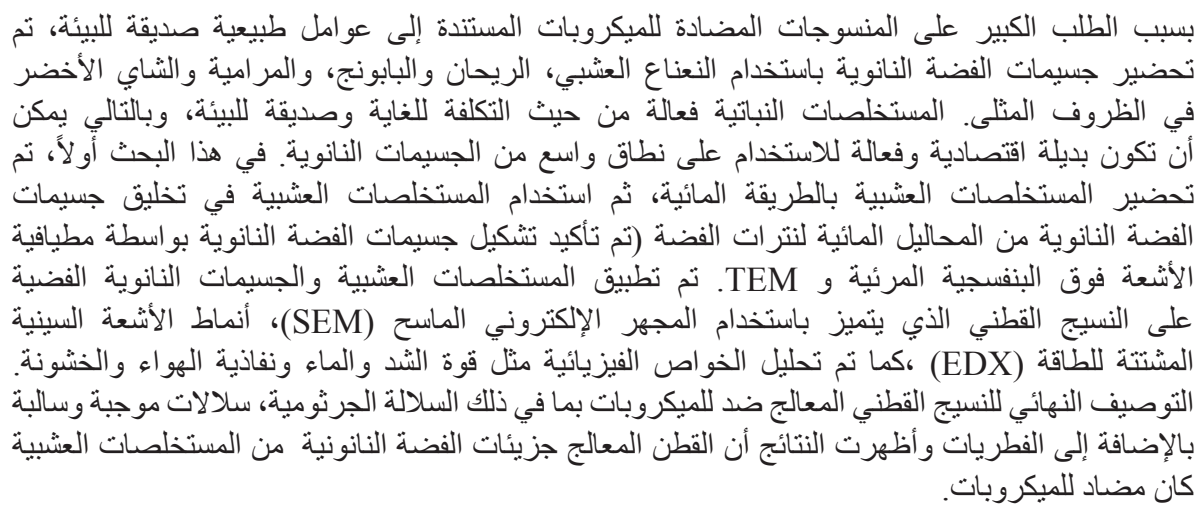

Egypt. J. Chem. 61, No. 6 (2018) 